suggested a severe hypovolemic shock state but not an early indicator for shock.

Prehosp Disaster Med 2019;34(Suppl. 1):s161-s162

doi:10.1017/S1049023X19003662

Radiation: Preparing for the Glow That You Can't See Dr. Kelly Klein, Dr. Raymond Swienton, Dr. Lindsay Flax, Dr. E. Liang Liu

Division of Emergency and Disaster Global Health, Department of Emergency Medicine, University Of Texas Southwestern Medical Center, Dallas, United States

Introduction: In 2013, a multinational collaboration met to improve the global and nation-specific preparedness and response in managing casualties from nuclear and radiological disasters. From this meeting, a survey was developed and distributed in both Japanese and English. The results published four years later illustrate a lack of understanding about radiation and risks to the health care provider.

Aim: To dispel myths and increase understanding regarding trauma treatment and healthcare risks for healthcare providers during a radiologic event.

Methods: IRB approved survey and literature review

Results: A total of 418 surveys were analyzed. Although $44 \%$ of participants acknowledged that they had taken at least one radiological training course, the majority of the respondents were still not comfortable with radiological emergencies.

Discussion: Despite the plethora of both online and in-person radiological training availability, healthcare providers are not comfortable with the topic. Based on information from the survey, it is important to dispel myths and educate healthcare providers so that they have reasonable expectations regarding risks and to ensure that they are comfortable coming to work. By doing this, there will be an adequate healthcare presence to help take care of patients who are not only in need of immediate trauma and radiologic exposure care but also with non-affected patients coming for emergent and scheduled health care needs. Prehosp Disaster Med 2019;34(Suppl. 1):s162

doi:10.1017/S1049023X19003674

Real-Time GIS for Health Disaster Response in the Largest Archipelagic Country

Dr. Ahmad Alim ${ }^{1,2}$

1. Muhammadiyah Disaster Management Center, Yogyakarta, Indonesia

2. Ahmad Dahlan University, Yogyakarta, Indonesia

Introduction: Besides being located on the Pacific Ring of Fire, Indonesia is the largest archipelago country in the world. Some parts of the country are not very accessible. It raises difficulties in controlling and monitoring a disaster response mission remotely in real-time. Muhammadiyah, the Indonesian nongovernmental organization (NGO) that has been responding to disaster since 1919, used Geographic Information Systems (GIS) for Health Disaster Response (HDR) in the Lombok Earthquake 2018, in cooperation with ESRI Indonesia, as one alternative to disaster response controlling and monitoring.
Aim: To show the benefit of using real-time GIS for HDR in an archipelago country.

Methods: While responding to the disaster in Lombok, the Muhammadiyah Health Disaster Response Team was collecting data of patient, medication, problem, need, location, and resource with computers and smartphones, inputting the data that was forwarded to the ArcGIS platform. The Health Disaster Response Team coordinator and Muhammadiyah Board monitored and analyzed the health response through the GIS dashboard in Yogyakarta, $652 \mathrm{~km}$ far from Lombok Island.

Results: Using real-time GIS has been useful for disaster response. It was efficient by cutting flight and other transport costs, connected by the internet, and communicative by graphic and map dashboard. It was a green approach since it was paperless, and analysis-friendly by real-time data compilation and computation.

Discussion: One of the big gaps in disaster response monitoring seems to be real-time data. Especially in an archipelago country, it is costly, time-consuming, and resource consuming. Daily big data may be frustrating and can become "white paper syndrome." One of the good approaches to that is GIS Web services although it must be realized that the internet connection in a rural area can be another challenge. It can be solved by in-gadget data memory that can be delivered while the internet connection is available.

Prehosp Disaster Med 2019;34(Suppl. 1):s162

doi:10.1017/S1049023X19003686

\section{Regional Engagement Program: Supporting Local Leadership and Building Local Skills and Knowledge in Order to Develop a Systematic Approach to Disaster Medical Management}

Ms Lisa Vermeulen, Associate Professor Dianne Stephens

National Critical Care and Trauma Response Centre, Tiwi, Australia

Introduction: One of the key components in any effective disaster response is the capacity of local communities to respond in a timely and efficient manner. Over the last 3 years, the National Critical Care and Trauma Response Centre in Darwin has been involved in building regional capacity across the Asia-Pacific, supporting local leadership and building local skills and knowledge in order to develop a systematic approach to disaster medical management.

Aim: This presentation is to describe the Regional Engagement Program, its strengths, weaknesses, and outcomes.

Methods: We will describe the background to the program, the process for regional engagement and the Results of our evaluation. The program used the Major Incident Medical Management Systems (MIMMS) approach which was delivered in-country and included identifying and using local personnel to deliver the program. The program was conducted across the region in Myanmar, Fiji, Tonga, Vanuatu, Samoa, Timor, and Indonesia. Initially the courses were run by personnel from Australia but through engagement with local Ministries of Health and collaboration with identified key 